\title{
Dinâmica do perfilhamento do capim-marandu cultivado em duas alturas e três intervalos de corte
}

\author{
Gelson dos Santos Difante ${ }^{1 *}$, Domicio do Nascimento Júnior ${ }^{2}$, Sila Carneiro da Silva ${ }^{3}$, \\ Valéria Pacheco Batista Euclides ${ }^{4}$, Anderson de Moura Zanine ${ }^{1}$, Bruna Adese ${ }^{1}$
}

\footnotetext{
1 Programa de Pós-graduação em Zootecnia - UFV. Bolsista CNPq.

2 Departamento de Zootecnia, UFV. Bolsista CNPq.

${ }^{3}$ Departamento de Zootecnia, USP/ESALQ.

${ }^{4}$ Embrapa Gado de Corte, Campo Grande, MS.
}

RESUMO - O experimento foi realizado para avaliar a dinâmica do perfilhamento do capim-marandu submetido a duas alturas $(15$ e $30 \mathrm{~cm}$ ) e três intervalos de corte (aparecimento de três, quatro e cinco folhas por perfilho). Utilizou-se delineamento de blocos completos casualizados com três repetições e arranjo fatorial $2 \times 3$. As avaliações consistiram do monitoramento mensal do aparecimento e morte de perfilhos em duas touceiras por parcela, sendo os novos perfilhos classificados em basilares e aéreos. A altura de corte de $15 \mathrm{~cm}$ promoveu maior aparecimento, 1,46 perfilhos/100 perfilhos.dia, e maior mortalidade de perfilhos, 0,368 perfilhos/100 perfilhos.dia. O intervalo de cortes de 5 folhas/ perfilho resultou em menor taxa de aparecimento de perfilhos totais quando associado à altura de corte de $30 \mathrm{~cm}, 0,97$ perfilhos/100 perfilhos.dia. Parcelas cortadas a $15 \mathrm{~cm}$ de altura apresentaram menor variação em densidade populacional de perfilhos, independentemente do intervalo de corte utilizado. A dinâmica de perfilhamento basilar, aéreo e total respondeu de forma diferenciada ao intervalo e à altura de corte, resultado do estádio fisiológico das plantas e das condições ambientais vigentes durante o experimento.

Palavras-chave: ecofisiologia, gerações de perfilhos, índice de estabilidade

\section{Tillering dynamics of marandu palisadegrass submitted to two cutting heights and three cutting intervals}

\begin{abstract}
The study was conducted to evaluate the dynamics of the tillering process in marandu palisadegrass submitted to two cutting heights $(15$ and $30 \mathrm{~cm}$ ), and three cutting intervals (leaf appearance intervals of three, four and five leaves per tiller). A complete randomized block design, with three replications and a $2 \times 3$ factorial arrangement was used. Evaluations consited of monthly measurements of tiller appearance and death in two tussocks per plot, with new tillers sorted into basal and aerial tillers. Cutting at $15 \mathrm{~cm}$ resulted in higher tiller appearance, 1.46 tiller/100 tiller.day, and death rates, 0.368 tiller/100 tiller.day. The five-leaf cutting interval resulted in the lowest tiller appearance rate when associated with the $30 \mathrm{~cm}$ cutting height, 0.97 tiller/100 tiller.day. Swards cut at $15 \mathrm{~cm}$ presented smaller variations in tiller population, regardless of the cutting frequency used. The dynamics of basal, aerial and total tillering responded differently to cutting frequency and intensity, consequence of the physiological state of plants and prevailing environmental conditions during the experiment.
\end{abstract}

Key Words: ecophysiology, stability index, tiller generations

\section{Introdução}

A espécie Brachiaria brizantha (Hochst. ex A. Rich) destaca-se no cenário nacional por apresentar elevada produção de forragem em solos cuja fertilidade varia de média a baixa (Soares Filho et al., 1992). O conhecimento sobre a ecofisiologia e a ecologia do pastejo dessa forrageira é uma importante ferramenta de manejo, pois permite melhor entendimento da produção vegetal e de sua utilização pelo animal em pastejo (Da Silva, 2004).

A compreensão do processo de acúmulo de forragem de um pasto, aliado às diferentes respostas ao processo de pastejo, determina o conhecimento das respostas das gramíneas tropicais ao manejo a que são impostas. O aparecimento de folhas, o alongamento de folhas e de colmos e a duração de vida das folhas são as características morfogênicas

Este artigo foi recebido em 1/11/2006 e aprovado em 13/8/2007. 
que determinam diretamente o crescimento das plantas forrageiras. O número de folhas vivas por perfilho, o comprimento final das folhas e a densidade populacional de perfilhos são as variáveis estruturais influenciadas diretamente pelas características morfogênicas, e constituem o índice de área foliar de um pasto, cuja importância é central para o crescimento das gramíneas (Lemaire \& Chapman, 1996).

A manipulação do processo de desfolhação por ajustes e combinações entre freqüência e intensidade de corte ou pastejo pode gerar respostas diferenciadas em acúmulo e valor nutritivo da forragem produzida, promovendo variações em área foliar a partir de alterações nos padrões demográficos de perfilhamento das plantas forrageiras.

As variáveis morfogênicas são afetadas pela disponibilidade de recursos de crescimento como água, luz, nitrogênio e temperatura. As variáveis estruturais, por sua vez, são afetadas pelas modificações nas respostas morfogênicas e pela freqüência e intensidade de corte ou pastejo. Pastos mantidos sob regime intenso de desfolhação apresentam perfilhos com folhas mais curtas e maior densidade populacional de perfilhos pequenos, ao passo que sob regime leniente de desfolhação são observadas menores densidades populacionais de perfilhos grandes e folhas mais compridas (Matthew et al., 2000). Essas modificações estruturais promovem a manutenção da dinâmica de crescimento das plantas forrageiras e representam uma estratégia de adaptação ao pastejo, garantindo produtividade pela melhor captação dos recursos do meio, notadamente luz. Objetivou-se com este trabalho avaliar a dinâmica do perfilhamento do capim-marandu submetido a duas alturas e três intervalos de corte.

\section{Material e Métodos}

O experimento foi conduzido em área do Departamento de Zootecnia da Universidade Federal de Viçosa, MG, no período de agosto de 2003 a abril de 2004. O clima da região, segundo a classificação de Köppen, é Cwa, subtropical, com estações seca e chuvosa bem definidas. Os dados climáticos (Figura 1) foram obtidos na estação meteorológica do Departamento de Engenharia Agrícola, localizada no Campus da UFV, a 1.000 m da área experimental.

O extrato do balanço hídrico mensal (Figura 2) foi calculado com base nos dados de precipitação $(\mathrm{mm})$ e temperatura $\left({ }^{\circ} \mathrm{C}\right)$ média mensal do período experimental.

O solo da área experimental é classificado como Argissolo vermelho amarelo de textura franco-argilosa (EMBRAPA, 1999). Antes do estabelecimento das parcelas, foram colhidas amostras de terra na camada de 0 a $20 \mathrm{~cm}$ para determinação

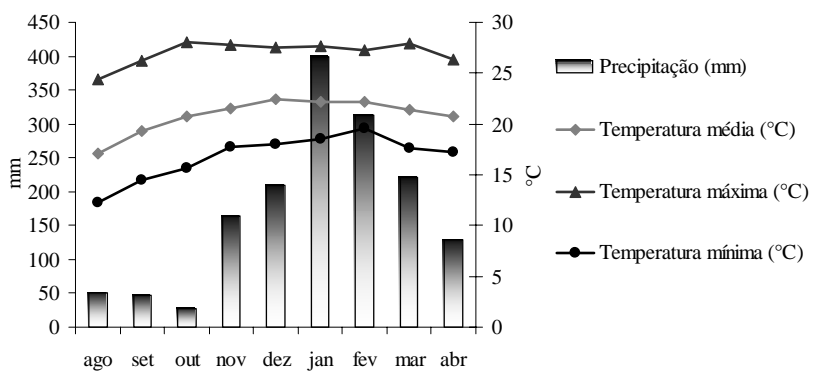

Figura 1 - Precipitação $(\mathrm{mm})$, temperaturas média, máxima e mínima $\left({ }^{\circ} \mathrm{C}\right)$ no local do experimento no período de agosto de 2003 a abril de 2004.

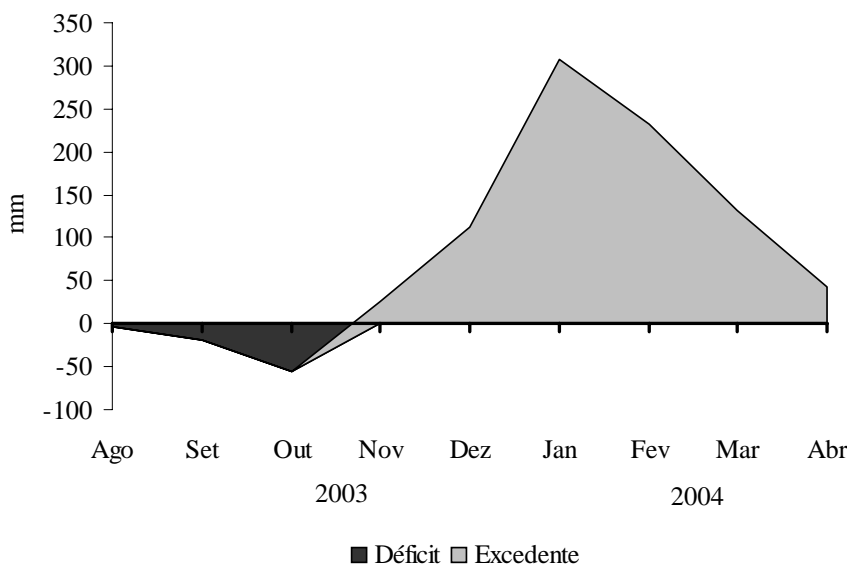

Figura 2 - Balanço hídrico mensal do local do experimento no período de agosto de 2003 a abril de 2004.

Tabela 1 - Características químicas do solo da área experimenta (profundidade de 0 a $20 \mathrm{~cm}$ )

\begin{tabular}{lc}
\hline Característica química & Resultado \\
\hline $\mathrm{pH}\left(\mathrm{H}_{2} \mathrm{O}\right)$ & 5,82 \\
$\mathrm{Ca}\left(\mathrm{cmol}_{\mathrm{c}} / \mathrm{dm}^{3}\right)$ & 3,25 \\
$\mathrm{Mg}\left(\mathrm{cmol}_{\mathrm{c}} / \mathrm{dm}^{3}\right)$ & 0,99 \\
$\mathrm{Al}\left(\mathrm{cmol}_{\mathrm{c}} / \mathrm{dm}^{3}\right)$ & 0,00 \\
$\mathrm{H}+\mathrm{Al}\left(\mathrm{cmol}_{\mathrm{c}} / \mathrm{dm}^{3}\right)$ & 6,14 \\
$\mathrm{Soma} \mathrm{de} \mathrm{bases}\left(\mathrm{cmol}_{\mathrm{c}} / \mathrm{dm}^{3}\right)$ & 4,30 \\
$\mathrm{CTC}\left(\mathrm{cmol}_{\mathrm{c}} / \mathrm{dm}^{3}\right)$ & 10,44 \\
Saturação por alumínio (\%) & 0,00 \\
Saturação por bases $(\%)$ & 41,2 \\
$\mathrm{P}-$ Mehlich-1 $\left(\mathrm{mg} / \mathrm{dm}^{3}\right)$ & 1,79 \\
$\mathrm{~K}-$ Mehlich-1 $\left(\mathrm{mg} / \mathrm{dm}^{3}\right)$ & 24,0 \\
\hline
\end{tabular}

da fertilidade do solo, cuja análise foi realizada no laboratório do Departamento de Solos da UFV (Tabela 1).

A correção da fertilidade do solo foi realizada por meio da aplicação de 1,1 t/ha de calcário dolomítico (PRNT = 83\%) objetivando elevar a saturação por bases para $50 \%$. A adubação fosfatada, na forma de superfosfato simples, foi realizada no momento do transplantio das mudas para 
a área experimental e o fertilizante aplicado em linha na quantidade de $100 \mathrm{~kg} / \mathrm{ha}$.

As sementes de Brachiaria brizantha cv. Marandu foram semeadas no mês de agosto em bandejas plásticas contendo substrato orgânico comercial e foram mantidas em casa de vegetação com irrigação diária até o transplantio na área experimental, no dia 16 de setembro de 2003. Foram utilizadas parcelas de $0,60 \mathrm{~m}^{2}(0,60 \times 1,00 \mathrm{~m})$ com um estande de 24 plantas por parcela e espaçamento de $20 \mathrm{~cm}$ entre linhas e $15 \mathrm{~cm}$ entre plantas.

Após o completo estabelecimento do estande, as plantas foram submetidas a um corte de uniformização na altura de $15 \mathrm{~cm}$. O corte referente aos tratamentos foi realizado 30 dias após o corte de uniformização, no dia 18 de outubro, época em que foram aplicados $50 \mathrm{~kg} / \mathrm{ha}$ de nitrogênio na forma de uréia.

Os tratamentos experimentais corresponderam a combinações entre duas alturas de corte $(15$ e $30 \mathrm{~cm})$ e três intervalos de corte, correspondentes ao período de tempo necessário para o surgimento de três, quatro e cinco folhas por perfilho, conforme descrito a seguir:

- $15 \mathrm{~cm} / 3$ folhas, $15 \mathrm{~cm} / 4$ folhas e $15 \mathrm{~cm} / 5$ folhas: altura de corte de $15 \mathrm{~cm}$ e intervalo de cortes para surgimento de três, quatro e cinco folhas, respectivamente.

- $30 \mathrm{~cm} / 3$ folhas, $30 \mathrm{~cm} / 4$ folhas e $30 \mathrm{~cm} / 5$ folhas: altura de corte de $30 \mathrm{~cm}$ e intervalo de corte para surgimento de três, quatro e cinco folhas, respectivamente.

Foram marcadas aleatoriamente em cada parcela duas touceiras, monitoradas mensalmente de forma a serem marcados com fios coloridos os perfilhos novos, distinguindo-se com cores diferentes de acordo com cada avaliação, as gerações de perfilhos. Obteve-se, assim, o número total de perfilhos, o número de perfilhos basilares e o número de perfilhos aéreos em cada avaliação. Foram calculadas as taxas de aparecimento e morte (perfilhos/100 perfilhos.dia) do número total de perfilhos (TApP e TMoP), dos perfilhos basilares (TApB e TMoB) e dos perfilhos aéreos (TApA e TMoA): $\mathrm{TApP}=$ perfilhos surgidos/total de perfilhos vivos na marcação anterior e $\mathrm{TMoP}=$ perfilhos mortos/total de perfilhos vivos na marcação anterior.

$\mathrm{O}$ índice de estabilidade $\left(\mathrm{P}_{1} / \mathrm{P}_{0}\right)$ da população de perfilhos foi calculado de acordo com a metodologia descrita por Bahmani et al. (2003) utilizando-se a expressão: $\mathrm{P}_{1} / \mathrm{P}_{0}=\mathrm{TSoP}(1+\mathrm{TApP})$, em que TSoP (taxa de sobrevivência de perfilhos) $=1-\mathrm{TMoP}$.

O período experimental foi subdividido em períodos, de outubro de 2003 a março de 2004, de acordo com as datas em que as avaliações do aparecimento e da mortalidade de perfilhos foram realizadas ( $0,40,85,115,150$ e 180 dias).
A dinâmica populacional de perfilhos totais, basilares e aéreos, bem como o índice de estabilidade, são apresentados utilizando-se estatística descritiva (médias) para cada período de avaliação.

Os dados foram analisados segundo o esquema fatorial em parcelas subdivididas no tempo, de modo que os tratamentos, combinações entre intensidade e freqüência de corte, constituíram as parcelas e os cortes constituíram as subparcelas. Utilizou-se o procedimento GLM do pacote estatístico SAS (SAS, 1993). Os comandos RANDON e TEST foram utilizados para a identificar e realizar os testes apropriados, de acordo com o delineamento especificado. As médias foram comparadas pelo teste Tukey a $5 \%$ de probabilidade. Para as taxas de aparecimento e mortalidade de perfilhos totais, basilares e aéreos, utilizou-se o seguinte modelo:

$\mathrm{Y}_{\mathrm{ijkl}}=\mu+\mathrm{F}_{\mathrm{i}}+\mathrm{I}_{\mathrm{j}}+\mathrm{FI}_{\mathrm{ij}}+\mathrm{B}_{\mathrm{k}}+\mathrm{e}_{\mathrm{a}}+\mathrm{P}_{\mathrm{l}}+\mathrm{FP}_{\mathrm{il}}+\mathrm{IP}_{\mathrm{jl}}+\mathrm{e}_{\mathrm{b}}$ em que $Y_{i j k l}=$ valor observado da freqüência $i$, intensidade j, bloco k no período $\mathrm{l} ; \mu=$ constante geral (média da população); $F_{i}=$ efeito da freqüência de desfolhação i, i = 1 , 2, 3; $\mathrm{I}_{\mathrm{j}}=$ efeito da intensidade $\mathrm{j}, \mathrm{j}=1,2 ; \mathrm{FI}_{\mathrm{ij}}=$ interação freqüência $\mathrm{i} \times$ intensidade $\mathrm{j}$; $\mathrm{B}_{\mathrm{k}}=$ efeito do bloco $\mathrm{k}, \mathrm{k}=1,2$, 3 ; $e_{a}=F B_{i j k}$, erro em que $F_{i}$, $I_{j}$ e $F_{i j}$ serão testados; $\mathrm{P}_{1}=$ efeito do período $\mathrm{l}, \mathrm{l}=1$, 2, 3; $\mathrm{FP}_{\mathrm{il}}=$ interação freqüência $\mathrm{i} \times$ período $\mathrm{l} ; \mathrm{IP}_{\mathrm{jl}}=$ interação intensidade $\mathrm{j} \times$ período $\mathrm{l}$; $\mathrm{e}_{\mathrm{b}}=\mathrm{FIBP}_{\mathrm{ijkl}}$, erro em que $\mathrm{P}_{\mathrm{l}}, \mathrm{FP}_{\mathrm{il}}$ e IP $\mathrm{I}_{\mathrm{jl}}$ será testado.

\section{Resultados e Discussão}

Os tratamentos $15 \mathrm{~cm} / 4$ folhas, $15 \mathrm{~cm} / 5$ folhas e $30 \mathrm{~cm} / 5$ folhas (Figuras 3B, C e F) permitiram apenas três cortes durante o período de avaliação, enquanto os tratamentos $15 \mathrm{~cm} / 3$ folhas, $30 \mathrm{~cm} / 3$ folhas e $30 \mathrm{~cm} / 4$ folhas (Figuras 3A, D e E) permitiram quatro cortes (Figura 3). A primeira geração correspondeu ao número de perfilhos existentes no dia da primeira marcação, cuja data de aparecimento não pôde ser identificada e, por isso, foi sempre mais numerosa. Observou-se diminuição mais drástica no número total de perfilhos da primeira geração a partir dos 85 dias de avaliação em todas as combinações de altura e intervalo de cortes avaliadas. A segunda geração apresentou, em geral, menor número de perfilhos quando comparada à primeira. A terceira geração apresentou-se mais vigorosa nos tratamentos de três e quatro folhas surgidas em comparação àqueles com o intervalo de corte de cinco folhas surgidas por perfilho, independentemente da altura de corte. A quarta geração apresentou-se mais vigorosa no intervalo de cortes de cinco folhas. A quinta e sexta gerações apresentaram comportamentos variáveis de acordo com as alturas de corte e 
o número de folhas surgidas. A sexta geração, avaliada no mês de março, apresentou número relativamente baixo de perfilhos e não pôde ser observada em todas as combinações de altura e intervalo de corte testadas, em virtude do número diferenciado de cortes para cada tratamento.

Foi observada interação período de avaliação $\times$ altura de corte $\times$ intervalo de corte $(\mathrm{P}=0,0021)$ para TApP e interação altura de corte $\times$ período de avaliação para TMoP $(\mathrm{P}=0,0335)$ (Figura 4). Maior TApP foi observada no tratamento $15 \mathrm{~cm} / 5$ folhas na avaliação realizada aos 115 dias (janeiro), quando a associação das alturas de corte e época do ano favorável à produção de forragem (Figuras 1 e 2) provavelmente contribuiu para maior entrada de luz na base do pasto, promovendo a ativação de gemas axilares e o aparecimento potencial de novos perfilhos, uma vez que a competição entre perfilhos ocorre sobretudo por luz (Sackville-Hamilton et al., 1995).

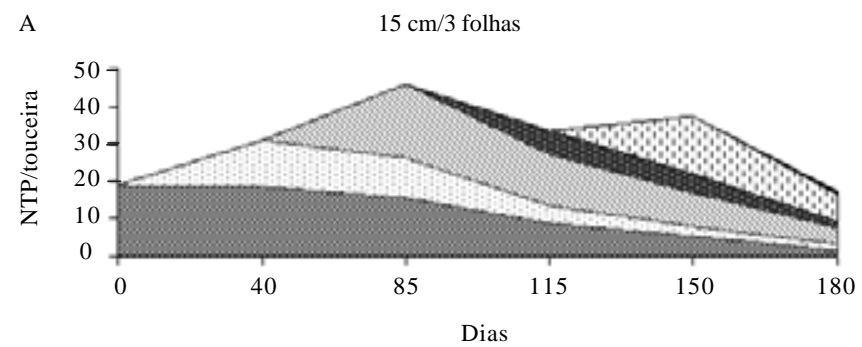

$15 \mathrm{~cm} / 4$ folhas

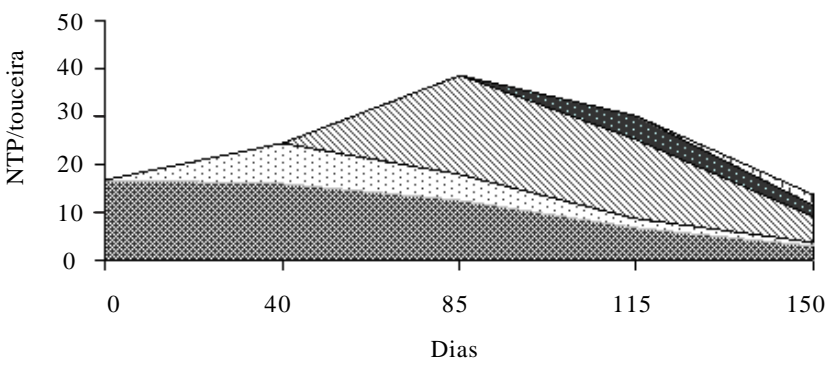

C

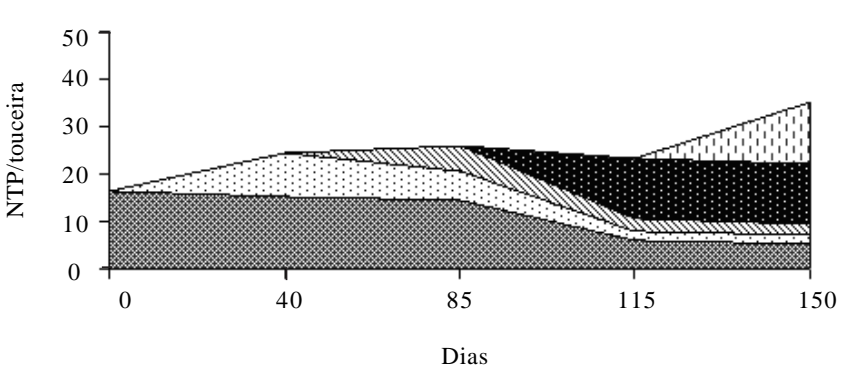

A altura de corte de $15 \mathrm{~cm}$ proporcionou TApP superior à altura de $30 \mathrm{~cm}(\mathrm{P}=0,0273)$. Houve efeito do corte na segunda avaliação (85 dias, novembro), quando as condições climáticas foram favoráveis ao desenvolvimento de novos perfilhos; além disso, a intensidade de corte de $15 \mathrm{~cm}$ promoveu maior abertura do dossel forrageiro em relação às parcelas manejadas com cortes a $30 \mathrm{~cm}$. Pastos mantidos mais baixos podem apresentar, além de maior TApP (Briske, 1991), maiores taxas de mortalidade de perfilhos (Carvalho et al., 2001), as quais são esperadas durante o período de verão e outono, determinando o mecanismo compensatório para a manutenção do equilíbrio da população de perfilhos frente à disponibilidade de luz e água (Murphy \& Briske, 1992; Cottignies \& Jennane, 1988).

A dinâmica populacional de perfilhos basilares (Figura 5) seguiu padrão semelhante àquele descrito para

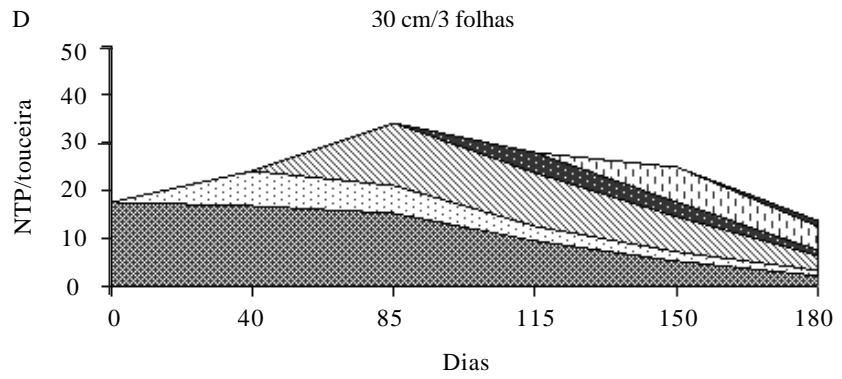

E $30 \mathrm{~cm} / 4$ folhas

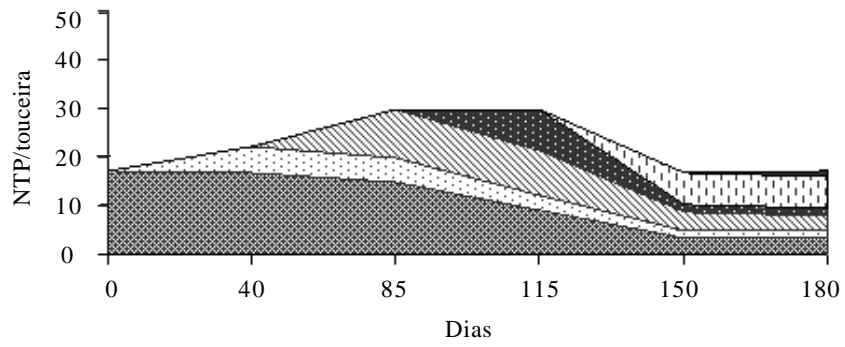

F $\quad 30 \mathrm{~cm} / 5$ folhas

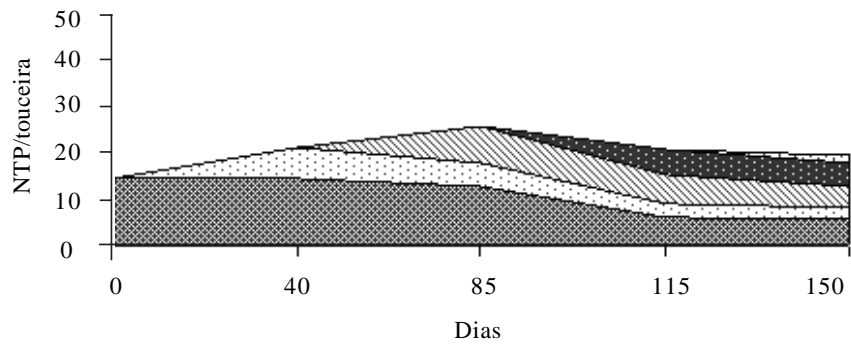

Figura 3 - Dinâmica populacional de perfilhos totais em capim-marandu submetido a duas alturas e três intervalos de cortes de out/2003 a abril/2004. 

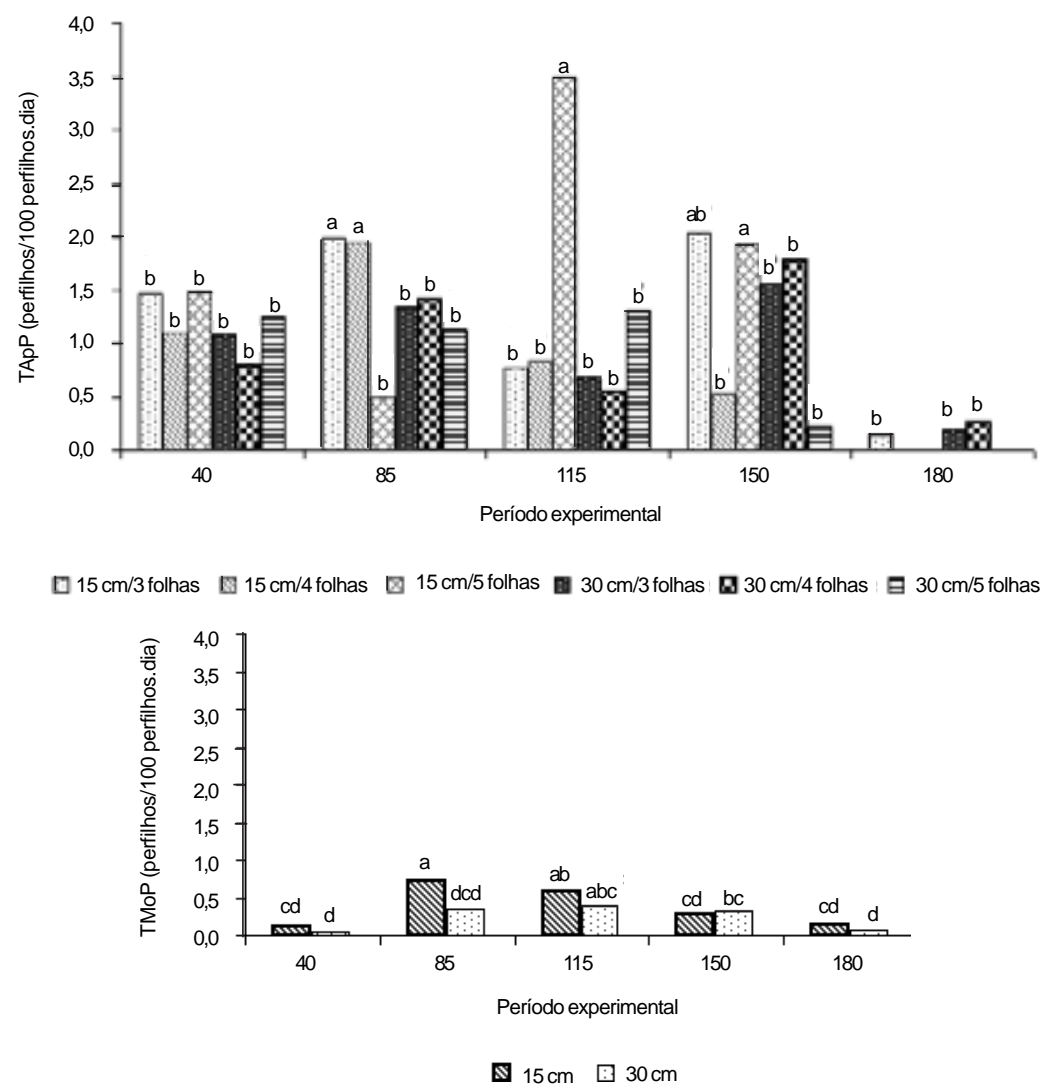

Figura 4 - Taxa de aparecimento e mortalidade de perfilhos totais (TApP e TMoP, perfilhos/100 perfilhos.dias) de capim-marandu submetido a duas alturas e três intervalos de corte de out/2003 a abril/2004.

a dinâmica de perfilhos totais. Na primeira geração, houve grande participação de perfilhos basilares, a qual foi reduzida gradativamente.

Houve interação intervalo de cortes $\times$ período de avaliação para TApB $(\mathrm{P}=0,0012)$ e para TMoB $(\mathrm{P}=0,0036)$ (Figura 6).

Independentemente da altura de corte avaliada, parcelas cortadas segundo o intervalo de cortes de cinco folhas surgidas por perfilho foram colhidas pela primeira vez aproximadamente aos 85 dias do início do experimento, quando o balanço hídrico do solo era positivo e, portanto, favorável ao acúmulo de forragem (Figura 2). Aliado à época do ano, o corte promoveu a abertura do dossel possibilitando a entrada de luz solar, fato que reconhecidamente promove a diferenciação das gemas axilares que dão origem a novos perfilhos (Matthew et al., 2000), notadamente perfilhos basilares. Com o avanço do período experimental, foi observado declínio nas taxas de aparecimento e mortalidade de perfilhos basilares para todos os intervalos de corte avaliados.

Na primeira avaliação, não foi observada a existência de perfilhos aéreos (Figura 7). Por ocasião da terceira marcação, os perfilhos aéreos representaram maior participação da população de perfilhos, exceto no tratamento 15 cm/5 folhas. O tratamento de $30 \mathrm{~cm} / 4$ folhas não apresentou perfilhos aéreos na terceira geração.

Houve interação período de avaliação $\times$ intervalo de cortes ( $\mathrm{P}=0,0024)$ para TApA (Figura 8 ). Para TMoA não foram detectadas interações período de avaliação $\times$ intervalo de cortes nem período de avaliação $\times$ altura de corte $(\mathrm{P}>0,05)$. Houve diferença entre períodos de avaliação para TMoA $(\mathrm{P}=0,0220)$. Os primeiros cortes foram decisivos para o estímulo ao aparecimento de perfilhos aéreos para os intervalos de corte de três e cinco folhas surgidas por perfilho, uma vez que a remoção do meristema apical pode ter estimulado o desenvolvimento de gemas e promovido o aparecimento de perfilhos. Por outro lado, o estímulo ao perfilhamento pode ocorrer também em resposta à desfolhação, mesmo quando os meristemas apicais não são removidos (Bulter \& Briske, 1988).

Nos meses de dezembro e janeiro, foram registradas as maiores taxas de aparecimento e mortalidade de perfilhos aéreos, sugerindo maior renovação de tecidos, favorecida pelo aumento da temperatura e precipitação. Nesse mesmo período, foram registrados aumentos em mortalidade do número total de perfilhos, o que reflete o comportamento de perfilhos basilares (Figuras 3 e 4) e aéreos (Figuras 7 e 8) e 
A

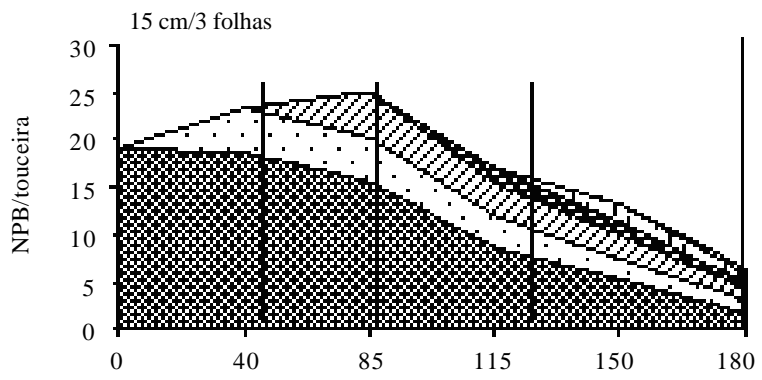

B

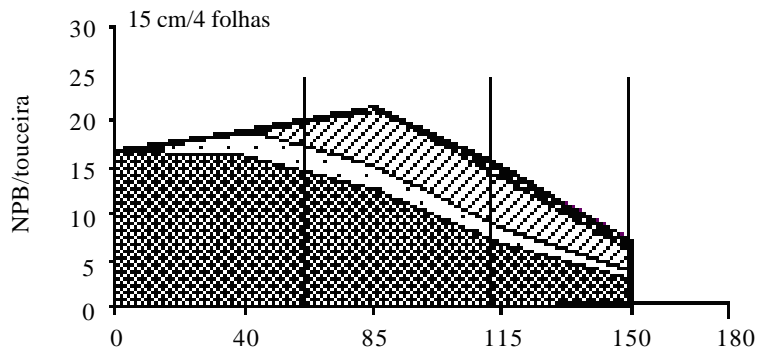

C

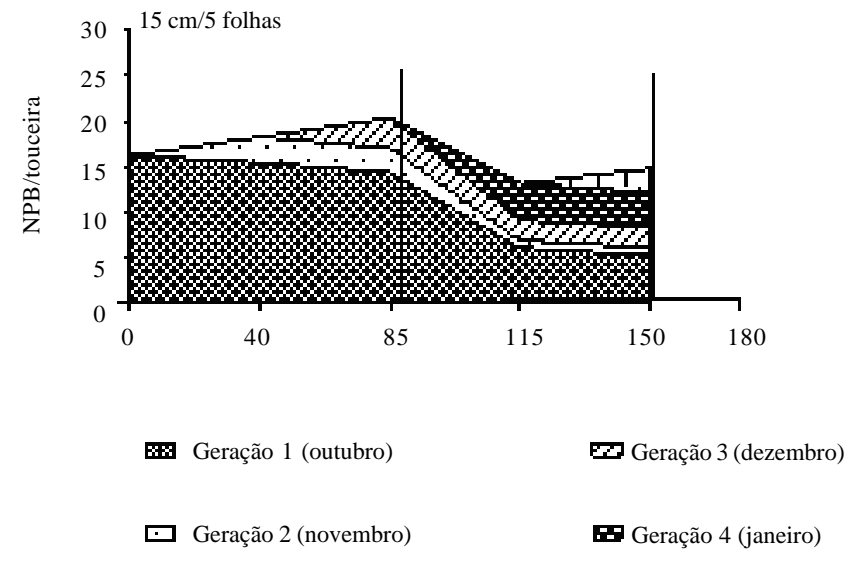

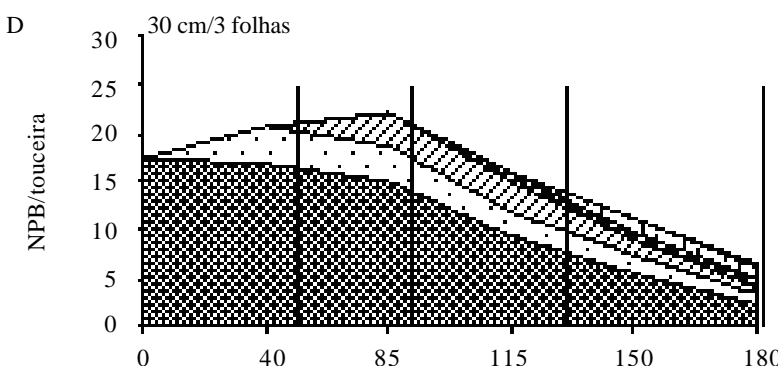

E $\quad 30,30 \mathrm{~cm} / 4$ folhas

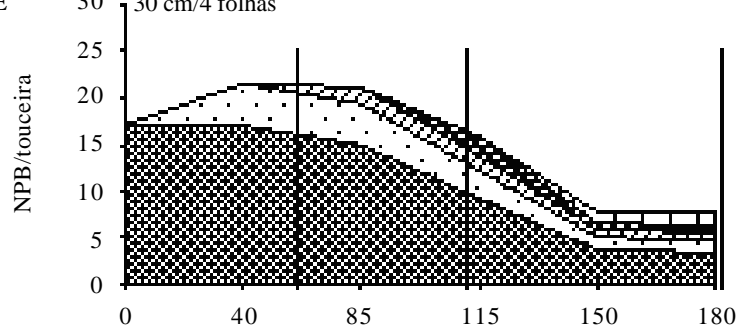

F $30,30 \mathrm{~cm} / 5$ folh

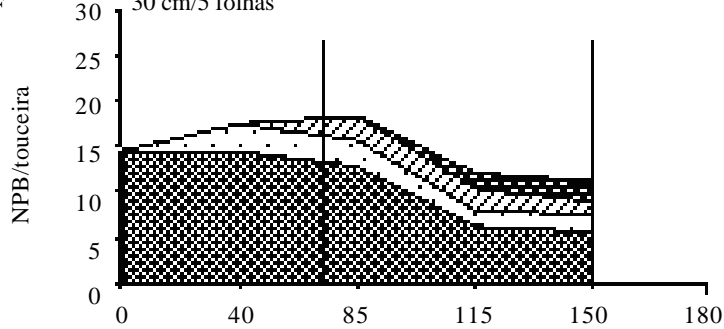

미 Geração 5 (fevereiro)

Geração 6 (março)

Figura 5 - Dinâmica populacional de perfilhos basilares em capim-marandu submetido a duas alturas e três intervalos de corte de out./2003 a abril/2004.

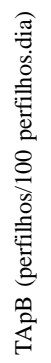

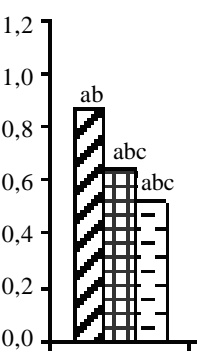

40

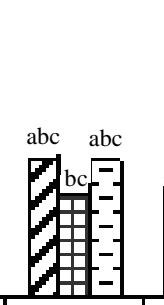

85

Período experimental

口. 3 folhas 甲 4 folhas

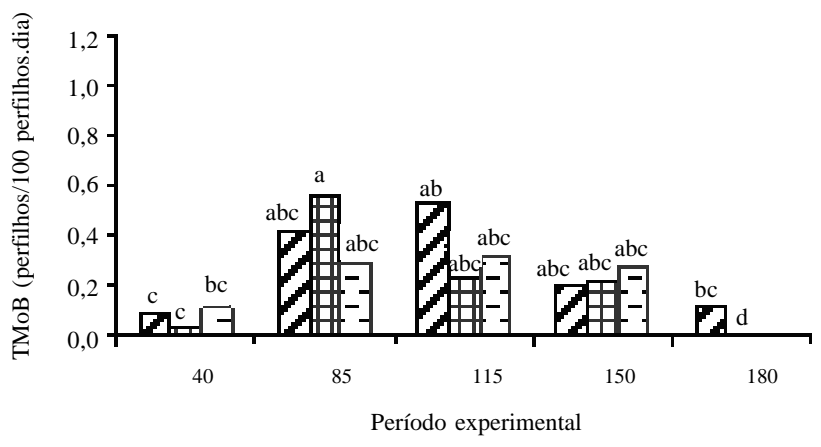

ㅁ 3 folhas $\mathbf{9} 4$ folhas $\mathbf{5}$ folhas

Médias seguidas de mesmas letras não diferem $(P>0,05)$ pelo teste Tukey.

Figura 6 - Taxa de aparecimento e mortalidade de perfilhos basilares (TApB e TMoB, perfilhos/100 perfilhos.dia) de capim-marandu submetidos a duas alturas e três intervalos de corte de out/2003 a abril/2004. 
A

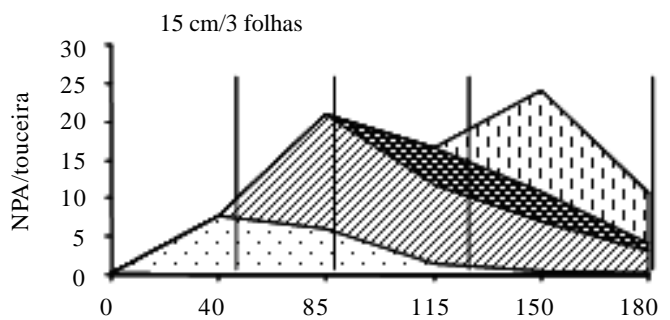

B

C
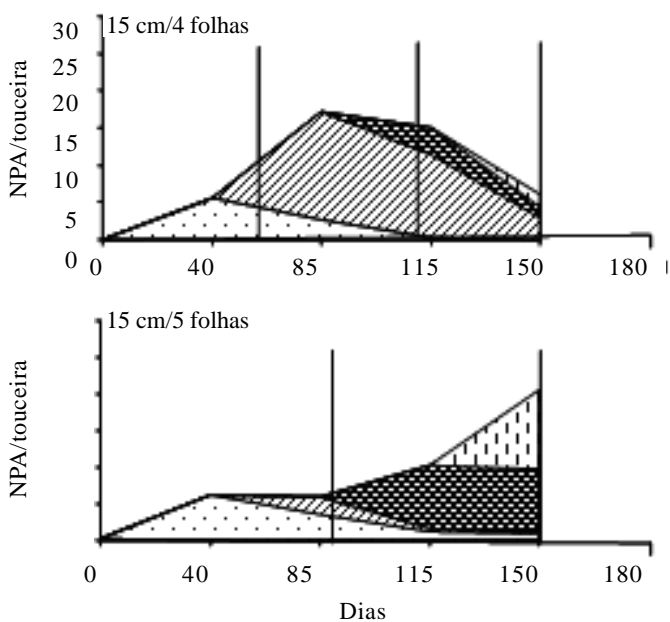
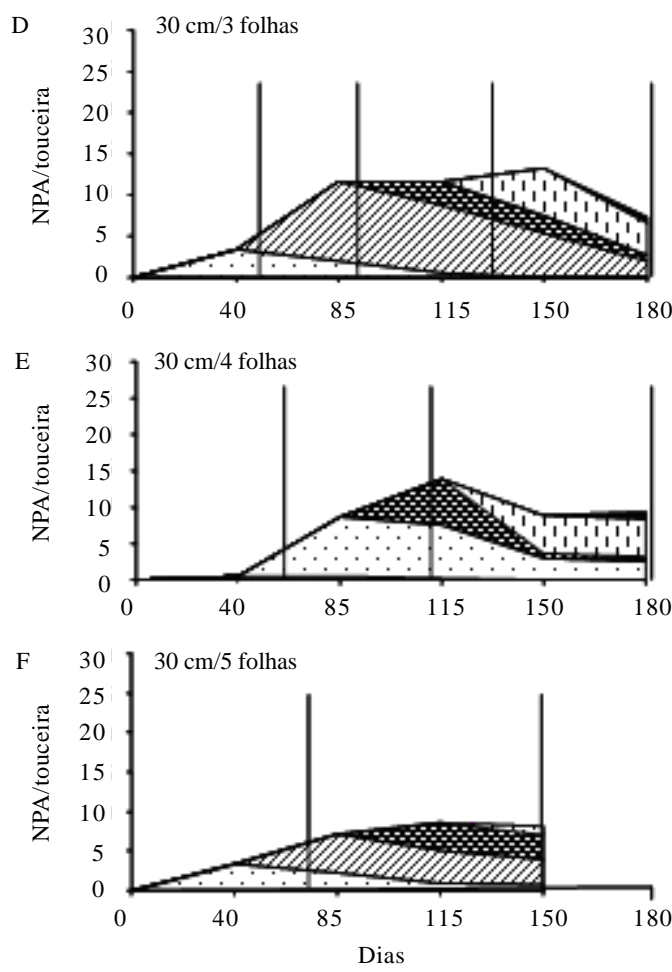

미 Geração 5 (fevereiro)

Geração 6 (março)

Figura 7 - Dinâmica populacional de perfilhos aéreos em capim-marandu submetido a duas alturas e três intervalos de corte de out/2003 a abril/2004.
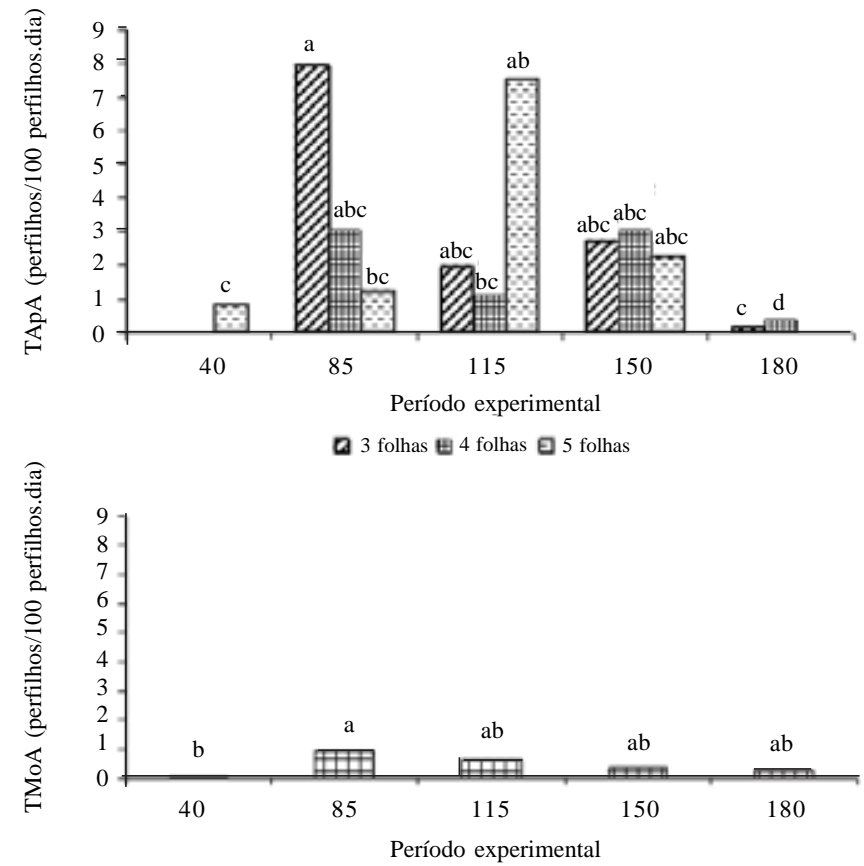

曲 TMoA

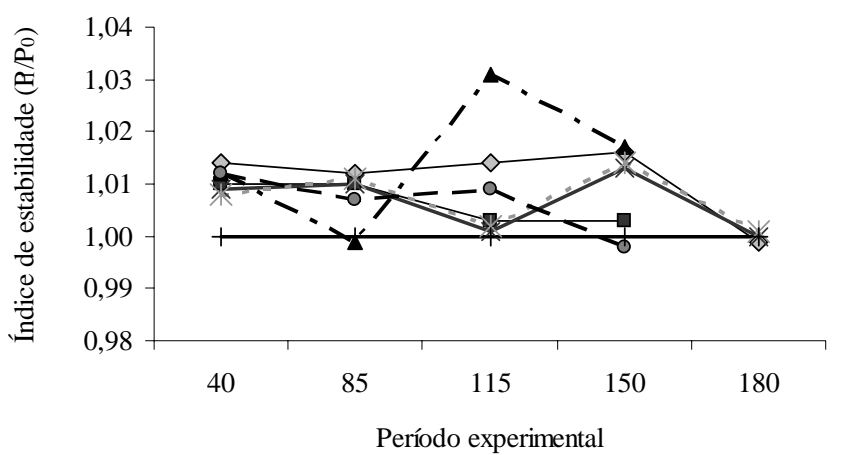

$\sim-15 \mathrm{~cm} / 3$ folhas $\longrightarrow-15 \mathrm{~cm} / 4$ folhas $\quad \longrightarrow-15 \mathrm{~cm} / 5$ folhas

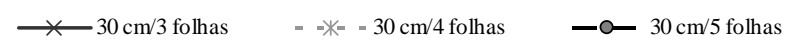

Figura 8 - Taxa de aparecimento e mortalidade de perfilhos aéreos (TAPA e TMoA, perfilhos/100 perfilhos.dias) de capim-marandu submetido a duas alturas e três intervalos de corte de out/2003 a abril/2004.
Figura 9 - Índice de estabilidade da população de perfilhos de capim-marandu cultivado em duas alturas e três intervalos de corte. 
suas contribuições relativas para a população de perfilhos que formavam o dossel da parcela. A decapitação de perfilhos basilares e o início do período reprodutivo do capimmarandu coincidiu com maior aparecimento de perfilhos aéreos, os quais se desenvolvem nos colmos reprodutivos decapitados, que servem de substrato para seu desenvolvimento.

A produção de perfilhos aéreos representou proporção elevada da população total de perfilhos (34 a 56\%). Entretanto, esses perfilhos são pequenos e de vida curta, surgem em época do ano não favorável ao crescimento e, apesar de sua alta participação na população, contribuem pouco para a produção de forragem. Contudo, essa é uma premissa que precisa ser avaliada para que o processo de perfilhamento aéreo nessas plantas possa ser melhor compreendido.

É possível que diferenças não significativas em taxas de aparecimento e morte de perfilhos possam, quando combinadas, resultar em variações significativas em densidade populacional de perfilhos, razão pela qual é importante avaliar o efeito conjunto de ambos. Isso pode ser feito por meio do índice de estabilidade da população (Bahmani et al., 2003). Valores do índice de estabilidade da população (Figura 9) inferiores a 1,0 indicam que a sobrevivência, aliada ao aparecimento de novos perfilhos, não é suficiente para compensar as taxas de mortalidade e que a população tenderia a diminuir. Por outro lado, valores maiores que 1,0 indicam situação inversa e valores próximos de 1,0 indicam uma população de perfilhos estável, em que o número de perfilhos praticamente não varia, apesar de ser resultado de um equilíbrio dinâmico (Bahmani et al., 2003).

O índice de estabilidade do capim-marandu manteve-se acima de 1,0 durante todo o período experimental. Porém, seus valores diminuiram à medida que o período experimental avançou, o que pode ser resposta à época do ano e ao início do período reprodutivo do capim, modificando as relações entre taxas de aparecimento e mortalidade de perfilhos. Ao contrário do que se esperava, parcelas manejadas sob altura de corte de $30 \mathrm{~cm}$ apresentaram tendência a índice de estabilidade menor que 1,0 ao final do período experimental, provavelmente por características relacionadas ao sombreamento de perfilhos e folhas, promovendo sua morte nessa época do ano, em que ocorre maior competição por água e luz entre perfilhos.

\section{Conclusões}

A altura de corte de $15 \mathrm{~cm}$ aumenta a velocidade de renovação de tecidos, elevando as taxas de aparecimento e de mortalidade de perfilhos. Seus efeitos, contudo, são modulados pelas condições ambientais e pelas combinações entre intensidades e freqüências de corte. Parcelas cortadas a $15 \mathrm{~cm}$ de altura apresentam populações mais estáveis de perfilhos, com menor variação em densidade populacional quando as condições fenológicas e ambientais se tornam limitantes para a sobrevivência de perfilhos.

\section{Literatura Citada}

BAHMANI, I.; THOM, E.R.; MATTHEW, C. et al. Tiller dynamics of perennial ryegrass cultivars derived from different New Zealand ecotypes: effects of cultivars, season, nitrogen fertilizer, and irrigation. Australian Journal of Agricultura Research, v.54, n.8, p.803-817, 2003.

BRISKE, DD. Developmental morphology and physiology of grasses. In: HEITSCHMIDT, R.K.; STUTH, J.W. (Eds.) Grazing management: an ecological perspective. Portland: Timber Press, 1991. p.85-108.

BULTER, J.L.; BRISKE, D.D. Population structure and tiller demography of the buchgrass Schizachyrium scoparium in response to herbivory. Oikos, v.51, p.306-312, 1988.

CARVALHO, C.A.B; DA SILVA, S.C.; SBRISSIA, A.F. et al. Demografia do perfilhamento e acúmulo de matéria seca em coastcross submetido a pastejo. Pesquisa Agropecuária Brasileira, v.36, n.3, p.567-575, 2001.

COTTIGNIES, A.; JENNANE, A. Water content, water potential, and transition from the noncycling to the cycling state in the pea cotiledonary bud. Journal of Plant Physiology, v.132, p.1-4, 1988.

DA SILVA, S.C. Fundamentos para o manejo do pastejo de plantas forrageiras dos gêneros Brachiaria e Panicum. In: GRASSALAND ECOPHYSIOLOGY AND GRAZING ECOLOGY, 2., 2004, Curitiba. Proceedings... Curitiba: Universidade Federal do Paraná, 2004. p.1-6.

EMPRESA BRASILEIRA DE PESQUISA AGROPECUÁRIA EMBRAPA. Sistema brasileiro de classificação de solos Brasília: 1999. 412p. (Produção de Informação).

LEMAIRE, G.; CHAPMAN, D. Tissue flows in grazed plant communities. In: HODGSON, J.; ILLIUS, A.W. (Eds.) The ecology and management of grazing systems. Wallingford: CAB International, 1996. p.3-36.

MATTHEW, C.; ASSUERO, S.G.; BLACK, C.K. et al. Tiller dynamics of grazed swards. In: LEMAIRE, G.; HODGSON, J.; MORAES, A.; CARVALHO, P.C.F.; NABINGER, C. (Eds.) Grassland ecophysiology and grazing ecology. Wallingford: CABI Publishing, 2000. p.127-150.

MURPHY, J.S.; BRISKE, D.D. Regulation of tillering by apical dominance - chronology, interpretive value, and current perspectives. Journal of Range Management, v.45, n.5 p.419-429, 1992.

SACKVILLE-HAMILTON, N.R.; MATTHEW, C.; LEMAIRE, G. In defence of the-3/2 boundary rule: a re-evaluation of self thinning concepts and status. Annals of Botany, v.76, p.569577, 1995.

STATISTICAL ANALYSIS SYSTEM - SAS. SAS/STAT - user's guide statistics. versão 6, 4.ed, Cary: 1993. v.1, 946p.

SOARES FILHO, C.V.; MONTEIRO, F.A.; CORSI, M. Recuperação de pastagens degradadas de Brachiaria decumbens. 2. Variação sazonal de parâmetros bioquímico-fisiológicos. Pasturas Tropicales, v.14, n.2, p.7-13, 1992 